\title{
The Neglected Patent Controversies in the Twenty First Century
}

\author{
Birgitte Andersen \\ Senior Lecturer in Department of Management and Director of E-commerce Programme, \\ Birkbeck - University of London - Department of Management
}

\section{ABSTRACT}

At the turn of the century we have seen a tightening of the patent system. However, policy makers systematically neglect the patent controversies. This article critically reviews the complex relationships between the rationales for patent rights on the one hand, and the social and economic effects of such on the other hand. Only when we understand this relationship, will we be able to design appropriate Intellectual Property Right (IPR) regimes for the new technoeconomic paradigm of knowledge-based micro-electronics and computer implemented pervasive inventions. Focus is on moral rationales, economic incentive rationales, increased competition and "market protection of entrepreneurial talent" rationales, and the economic rationales for organizing science, technology and creativity. It is argued that patent systems are not neutral, but set the rules of the game in which individuals and organizations are the players.

KeYwords $\quad$ Intellectual Property Rights (IPRs); Patent Rationales; Policy

JEL-CODES | O34, O38 


\section{RESUMO}

$\mathrm{Na}$ virada do século, assistimos a um reforço do sistema de patentes. No entanto, os gestores de políticas deixam sistematicamente de lado as controvérsias sobre patentes. Este artigo examina criticamente as complexas relações entre, por um lado, as razôes para os direitos de patente e, por outro lado, seus efeitos sociais e econômicos. Só quando entendermos essa relação, seremos capazes de projetar regimes adequados de Direitos de Propriedade Intelectual (DPI) para o novo paradigma tecnoeconômico de microeletrônica baseada em conhecimento e invençōes de amplo alcance implementadas por computador. $O$ foco se concentra nas razões morais, nas razões de incentivo econômico, e nas razões de aumento da concorrência e "proteção do talento empresarial no mercado", e nas razōes econômicas para organizar ciência, tecnologia e criatividade. Afirma-se aqui que os sistemas de patentes não são neutros, eles estabelecem as regras do jogo em que indivíduos e organizações são os jogadores.

Palavras-chave | Direitos de Propriedade Intelectual (DPI); Sistemas de Patentes; Política

Código JeL | O34, O38

\section{Introduction}

Entering a new electronic techno-economic paradigm in which knowledge assets rather than physical assets are the primary sources of wealth generation and economic growth, we have experienced a tightening of the patent system in terms of (i) integrating new areas of protection (even beyond science based principles, e.g. business methods patents), (ii) exclusive rights also on pure ideas (e.g. genetic codes and some mathematics) as well as (iii) increased period of protection. Fundamentally, the new form of competition in the new techno-economic paradigm imposed by new technological advances within micro-electronics has imposed new challenges for the patent regime, which is currently undergoing reformation with respect to the protection of computer implemented inventions.

The Commission of the European Union (EU) recently held hearings across the Member States, to get their opinions regarding policy on intellectual 
property protection of business methods and computer-implemented inventions. ${ }^{1}$ The problem formulation is essentially whether the EU shall be confined to harmonizing the relevant laws of the Member States on the patentability of business methods on the basis of the status quo as defined by the jurisprudence (i.e. as it is now in most member states of the EU) or if the EU shall extend the scope of application of the Directive as in the US or beyond:

- Option 1: Most European countries and Japan: A business method can be patented if it reflects a technical advance. In this sense, it is protected as software and computer programs (Criteria: The technical [digital] idea embedded in the business method has to be new and inventive; i.e. novel and non-obvious).

- Option 2: The US: Business methods can be patented as long as they are in "the technological arts"; that is, the business methods may not necessarily be of a technical character, but it needs to be implemented via computers/software to get the protection. This meets the UN's definition of technology: "a combination of equipment and knowledge" and is in line with the basic patent law principle. (Criteria: The business method idea has to be useful, concrete and tangible results have to be provided.)

However, more recently the US has turned towards:

- Option 3: US considerations: There should be no technical or technological restrictions on the patentability of business methods: Any new idea of doing business (i.e. business method) should be able to be patented (Criteria: The business method idea has to be useful and concrete). ${ }^{2}$

In this article it is argued that Intellectual Property Right (IPR) systems are not neutral, and that before we can design any appropriate IPR policy for the new electronic era we need to understand how IPRs set the rules of the game for the players in many knowledge-based sectors. We cannot simply assume that an IPR

\footnotetext{
See EU's hearing on "Industrial Property" and "The Economic Impact of Patentability of Computer Programs" (2002): http://europa.eu.int/comm/internal_market/en/indprop/studyintro.htm.

2 It follows that Amazon.com could not have obtained their patent for their "one-click system" in Europe under current legislation. The controversies regarding the various above options form part of this article.
} 
system is the best way of organizing inventive activity at the macro and micro economic level. Hence, the rationale for the IPR system and its relationship with corporate strategy is a central area which requires illumination.

However, policy makers as well as the socio-legal and economic literature have largely ignored the rationales for intellectual property rights (why we have them and what we want from them) in relation to the social and economic effects of such in the new electronic era. In the late nineteenth century, when the legislatures on the patent controversy was settled (and the opinions and beliefs on the social benefits of patents in particular became the point of departure if not authority), the agenda of professional meetings within economics rarely included debates on the social and economic effects of the IPR system. Economists turned to other questions, and the patent controversy disappeared from the economic literature. In 1950 Fritz Machlup and Edith Penrose argued that IPRs had become a part of juridical thinking (law) and that most other disciplines (economics, politics, engineering) had not been interested in understanding the role of IPRs, but had merely made passing references to the subject. Even, since then, only very little theoretical or empirical research has been published on that topic.

The basic arguments of classical economists entering this article have been cited in a number of writings, including those of Plant (1934), Machlup $\&$ Penrose (1950), Cheung in Palmer (1986), as well as the edited volumes of Towse \& Holzhauer (2002). The profound works of more recent writers cited in this article also include those of Kenneth Arrow, Robert Merges, Richard Nelson, Paul David, Richard Posner, Sidney Winter, and others.

The need for understanding the relationship between IPRs on the one hand, and the social and economic effects of such on the other hand, has also increased in importance as a consequence of globalization processes, globalization policies and harmonization of such. An aim should also be to understand the dynamic effects of the exploitation of IPRs on the general profile of corporate power, and the accountability of that power. Finally, an aim (not addressed in this article) should be to understand the dynamic effects of the exploitation of IPRs on less developed regions which have expressed problems with the global IPR system in its current form, and in particular the effects of the TRIPs-agreement. ${ }^{3}$

\footnotetext{
3 Agreements on Trade Related Aspects of Intellectual Property Rights (TRIPs) came into force in 1995 as a part of the Uruguay Round agreement. By the time all signatories are in full compliance each country is expected to have a system of IPR and effective enforcement consistent with internationally agreed norms and standards.
} 
Only when we understand those relationships, will we be able to recognize that IPR systems are not neutral, and be able to design appropriate IPR regimes and IPR policies for a new economy.

\subsection{Objective of article}

The objective of this article is to critically review the relationship between the rationales for patent rights on the one hand, and the social and economic effects of such on the other hand. Emphasis is on moral rationales (section 2), the economic incentive rationales (section 3), the increased competition and "market protection of entrepreneurial talent" rationales (section 4), and the economic rationales for organizing science, technology and creativity (section 5). Table 1 below provides an overview of the rationales discussed within the sections.

Patents on computer-implemented inventions including digital ideas and business methods, other electronics, and information-based ideas interact with forms of competition and corporate strategies. The nature of such interaction will be incorporated in the analysis. The concluding section 6 will draw attention to how beliefs in patent rights differ considerably regarding precise intent, scope and effect, and the problems this may cause in policy design for the electronic era.

TABLE 1. Rationales for patent rights summarized

Section 2. Moral rationales:

Human rights:

Section 3. Economic incentive rationales: The social benefits from patents:

Section 4. Increased competition and "market protection of entrepreneurial talent" rationales: Industrial development from patents:

Section 5. Economic rationale of organizing science, technology and creativity: Increased information spill-over:
- The "natural right" to claim the intellectual property.

- The natural right to compensation and reward.

- Incentives to invent, be creative and innovate, as well as motivating the direction of such.

- Incentive to use and allocate resources more efficiently.

- The innovation enhanced competition and "nature of ideas" argument.

- The "market protection of entrepreneurial talent" for industrial development rationale.

- "Incentives to disclose ideas" rationale.

- Rationale of uniformity, order, increased information, increased spill-over and better advice. 


\subsection{Why the patent context}

The exploitation of knowledge embodied in product and process innovations, in new ideas, or related to intangible assets and symbolic material, is in most mature economies protected through the use of intellectual property rights (IPRs). IPRs came about as a natural evolution from property rights on land, capital and labour. Intellectual property rights are important because they represent the legal mechanism for protecting (or enhance monopoly control over) many corporate assets.

IPRs designed to protect the inventor from exploitation of their knowledge embodied in, mainly industrial, product and process innovations mainly take form of patents. ${ }^{4}$ This article focuses on the rationales for protecting such ideas embodied in product and process innovations, especially in relation to the electronic era. Protection of ideas embodied in symbolic material and creative expression (protected mainly by copyrights and trademarks) and protection of effort (an important part of copyright law for data base protection) will not be discussed. Although information and communication technology have increased the scope for trademarks and copyrights, the patent system is still of primary importance, and increasing in relevance, for many traditional and new sectors operating in the electronic era.

That is, as argued by Andersen et al. (2000), the patent system took off with the rise of corporate capitalism and manufacturing in the nineteenth and the beginning of the twentieth century. However, the rise of the service and immaterial economy of symbolic material and creative expressions has boosted the relevance of trademarks and copyrights. Indeed in the 1960s-1980s, software programmes were protected via copyright law. However, as reverse engineering is easy for digital products and other computer implemented inventions, and as copyright law has a weak or no criteria for novelty on an idea in comparison

\footnotetext{
4 The legal aspects of the patents mostly used by sectors creating value within the electronic techno-economic paradigm are in accordance with the US case (http://www.uspto.gov) as follows: Patents: The right conferred by the patent grant is not the right to make, use, offer for sale, sell or import, but the right to exclude others from making, using, offering for sale, selling or importing the invention. A patent for an invention is the grant of a property right to the inventor. The term of a new patent is 20 years from the date on which the application for the patent was filed or, in special cases, from the date an earlier related application was filed, subject to the payment of maintenance fees. A patent has to reflect a technical novelty (that is, a movement of the technological frontier). A design patent is part of patent law. Such may be granted to anyone who invents a new, original, and ornamental design for an article of manufacture.
} 
to patent law, information technology firms found that copyright law was inadequate to protect their inventions or ideas. E.g. if IBM invested three hundred years (in terms of person hours worked) to develop a digital idea (e.g. software programme), it could be "reversed engineered" by the Japanese in ten minutes, and slightly amended for new copyright purposes, and such type of behaviour happened, IBM claimed at a meeting in the Danish Parliament in February 2002..$^{5}$ Thus, patent protection of the digital idea was considered as essential and there was a change in law regarding patent protection of software. ${ }^{6}$

Furthermore, one of the arguments regarding why business methods should be protected under patent law (as opposed to copy right law) has been to impose a novelty criteria regarding technical progress or advance, so that the idea is not easily imitated. However, if option 2 or 3 listed in the introduction above is adopted to the EU patent law, this will result in a fundamental change in the nature of patent law, making an exemption for the criteria of novelty. Similarly, much symbolic material and creative expression that service firms (e.g. retail, architecture, etc.), as well as some manufacturing (e.g. consumer electronics), previously protected via copyrights or trademarks have now also found a way to be protected by design patents. ${ }^{7}$

Thus, although protection of symbolic material and creative expression have increased the scope for copyrights and trademarks in the electronic age, the patent system protecting product and process inventions is still of primary importance, and even increasing in application, for most sectors in new economy. The rationales for protecting ideas embodied in product and process innovations, especially in relation to the electronic era, will now be discussed in detail.

\footnotetext{
5 The meeting was on the harmonization of EU's policy on computer-implemented inventions.

6 To illustrate how computer programs today can be protected via both patent and copyright law, let us imagine a software program developed to operate a machine painting cars. Let us first imagine that a software program was developed from analyzing the movements of a real person painting a car, and that the software program now can operate a machine doing the same job. As the software program idea is regarded as a technical progress it can obtain a patent, and the written source codes in the program can be protected by copyright law. Now let us imagine that someone writes a new and different program that can do the same job. Unless the new program is more efficient (e.g. in terms of speed or quality) it will not be able to be protected by patent law, as the technical progress idea is the same (i.e. it is not novel but obvious). Yet, the new program can still obtain a copyright on the written source codes as they are different from the other computer implemented idea. Hence, a software patent protects the technical progress idea, whereas the source codes within the program are protected by copyright law.

7 These were some of the results of the EU fifth framework project "Patents and services" (Contract no ERBHPV2-CT-1999-06).
} 


\section{Moral rationales: human rights}

With respect to moral rationales for IPRs, one argument is that the law should provide remedies against those who appropriate ideas of others. A person who has devoted time and effort to create something has a right to claim that thing (see 2.1. The "natural right" to claim the intellectual property, below), and also has a right to obtain some reward for all her work (see 2.2. The natural right to compensation and reward, below). The principal advocator for this idea was Jean-Baptiste-Ambroise-Marcellin Jobard who, in the beginning of the nineteenth century, wrote on the moral aspects of human rights.

\subsection{The "natural right" to claim the intellectual property}

Ideas are protected under the principle of "natural law", in the sense that somebody's idea is a "natural right". This connotation signals some kind of "property" and is to be seen in contrast to "positive law" where the society gives one some kind of "privilege". Thus, under this patent law rationale, a person has the natural property right on one's own idea and society is morally obligated to recognize and protect this property right. This can be compared to man's natural right to the fruits of his labour. Basically, everyone has a permanent and inalienable natural right to the sole disposal of himself and his work. The term "monautopoly" (meaning monopoly of oneself) is used. Thus, under natural law it is society's duty to protect the inventor, and (as discussed in section 2.2. The natural right to compensation and reward, below) to secure the inventor a fair share of the reward when exploiting the inventor's knowledge and ideas.

The name "intellectual property right" has some kind of respectable connotation "property", instead of the more unpleasant thing "monopoly privilege". Machlup \& Penrose (1950) argued that the term "intellectual property right" (as opposed to "intellectual monopoly privilege") was a very deliberate choice on the part of politicians working for the adoption of a patent law in the nineteenth century. This period was for liberty and equality and against privileges and monopolies of any sort. Intellectual property law 
on inventions based upon a "monopoly privilege" would be rejected, but as a "natural property right", the patent law would be justified or accepted. "What's in a name" is apparently important.

\section{Controversy:}

Whereas theory on natural rights is generally accepted for literary and artistic work as these have a perfectly decided character of individuality (or personality), and are therefore regarded as distinct works, it is often denied in relation to technological inventions. The basic argument is that technological inventions are mostly a social creation of collective, cumulative and interrelated work to which we all contribute, and therefore, no one person should be able to claim the property. Thus, it is proposed that the patent system decreases the moral rights for most subscribers to the system. This argument was put forward by John Lewis Ricardo (nephew of classical economist David Ricardo and member of the English Parliament), who argued for an abolishment of the IPR system in the mid/late nineteenth century. The argument was also put forward by Plant (1934). Andersen (2001) used patent statistics to illustrate how especially within electrical and electronics (including information and communication technologies, micro-electronics and electronic components) technological trajectories increasingly rely on broader knowledge bases, and have also become less concentrated in the sense that a range of different firms now participate in the same technological evolution. Thus the social origin of inventions (also termed distributed innovation processes) is a fact of life within electrical and electronic technological trajectories. Research on patent scope by Merges \& Nelson (1990) (discussed in section 4) has also revealed how inventions happen along multi-product trajectories that are cumulative, pathdependent and complex, in the sense that each innovation along the trajectory relies on own or others current or past ideas.

It closely follows that patents on technological inventions within electrical and electronics might be unfair, and actually against the principle of natural rights, as the IPR system in this case may prevent the inventors from using, or appropriating from, their own ideas they collectively have been part of creating, as someone else has been granted the IPR. 
Finally, the "human rights" argument has also often been challenged by the argument that, due to the specific nature of an idea (being non-rival and able to be consumed jointly just as a public good) there is no natural property on it. The argument emphasises that an intellectual property right on an idea is an artificial right imposed by government protecting the production and trade of things embodying the idea. Basically, intellectual property is about the "control of a market" for things employing ideas, and this has nothing to do with the natural property right argument.

\subsection{The natural right to compensation and reward}

As explained above, under "natural law" it is not only society's duty to protect the inventor, but also to secure the inventor a fair share of the reward when exploiting the inventor's knowledge. In this context, the inventor's effort ought to be both compensated and rewarded. The idea is that it would be immoral if the law lets everybody use the work of an inventor without her consent and without compensation or equivalent in return. The rationale is basically that justice requires that society compensate and reward its people for their services in proportion to what they cost and how useful they are to society. The system believers here consider the most appropriate way to secure inventors is by issuing IPRs.

\section{Controversy:}

However, it may be argued that it is a problem that the patent system is "general" and compensates and rewards equally all novel technological ideas. Although many inventions are the result of great effort, it has often been argued that there are also many accidental inventions and insignificant activities which do not deserve compensation and reward. Some even argue that a patent should only be allowed on inventions that are particularly expensive and particularly novel. However, in this article it is argued that most often inventions are generally not accidental. Scientists can hope for lucky accidents, but to invent the unthinkable and complex, scientists must specialise. Also, in IPR law today, inventions are not patentable if they are "obvious" meaning discoverable at low 
cost. Yet, the troublesome question of what ideas are novel enough to be granted patent protection will be faced with great challenges in the digital age. At one extreme, there is nothing new under the sun. At the other extreme, every different combination of digital ideas (e.g. source codes in software) or every different application of a digital idea (e.g. in music and computer games) constitutes a new idea. In specifying the criteria of patentability, the designers of any patent system must select a position somewhere on the spectrum marked by these extremes, and the problem-solving in this seems to be even more ambiguous within digital and micro-electronics where new combinations are produced more easily or with very little effort. This difficulty is also why many independent experts, as well as the software industry including IBM, are against a broad criteria regarding when a business method is eligible for a patent, as defined in option 2 and option 3 in section 1 of this article. ${ }^{8}$ Basically, the broadest option 3 even goes beyond the basic principles of current patent law, which is based upon a science-based principle of a technical or technological criteria. Experts would say that a too broad definition is not operational in practice. Without any technical criteria it is very difficult to judge an eligible criteria for granting a business method patent with respect to when it is novel and not obvious. With a vague novelty criteria we end up patenting too many trivial inventions, and the IPR system becomes inefficient. These are the concerns raised against the US system. However, when discussing the different options there is no conceptual reason why a business method needs to be technical or technological implemented (cf. options 1 and 2 in section 1). Many knowledgebased firms from finance, insurance and other business services operating in the EU would argue for implementing the US system in the EU. As argued by Navision, ${ }^{9}$ many of their inventions regarding new ways of doing business are very resource demanding and therefore need protection. Also, the competitive advantage from many of their inventions is in the way they do business (i.e. their business methods), and Navision sees no reason why such ideas should result in technical progress, although they are implemented via technology.

\footnotetext{
8 The issues were raised in a meeting in the Danish Parliament in February 2002, on the harmonization of EU's policy on computer-implemented inventions.

9 Navision participated in the meeting on the harmonization of EU's policy on computer implemented inventions in the Danish Parliament in February 2002.
} 
(Hence Navison supports option 2 in section 1). A matter for the knowledge intensive business services is also that the technical progress criteria on the legal protection of business methods (as defined in option 1 in section 1) place many knowledge-based business services in unfair competition against software firms, as software firms then will end up controlling the rights to all business methods as they master the technical part. Finally, in reality, there is not a clear line between, (i) when a business method is a technical advancement in itself, and (ii) when the method is of non-technical character but still an invention in technological art as it uses computers/software to be implemented. Hence, as reviewed by the EU (2002), many business methods inventions implemented via computers and software and patented in the US can be argued to be of a sufficient technical character to be patented in Europe and in Japan. It is evident that we are dealing with complex issues.

"The theory of the innovator's head-start profit" is also used as an argument against the reward rationale for industrial inventions. The argument is that if an inventor is really ahead of other inventions, then the time interval before catching up and imitation (which is difficult as it requires learning) should already secure the inventor profits and rent for her contribution; thus there is no need for governments to reward inventions in the first place. However, book-publishing, for example, where imitation is easy, would still need to be protected under "the theory of innovator's head-start profit" principle. The essential issue is the rate by which new ideas spread (i.e. the rate of imitation and catching up). The faster the speed, the more protection is needed to ensure reward. The slower the speed (e.g. due to learning requirements or "increasing returns to scale and adoption"dynamics), the less IPR protection is needed to ensure reward. As argued in the section 4.1. The innovation enhanced competition and "nature of ideas" argument (within section 4), the new electronic age is more prone to increasing returns dynamics and lock-in to particular trajectories, so reward from ideas can be appropriated without patent protection and unfair exploitation might occur.

However, the social origin of inventions is the strongest argument against reward to individual inventors. John Lewis Ricardo argued in the $\mathrm{mid} /$ late nineteenth century that, as all useful inventions depend less on 
any individual but build upon many peoples' contribution to the progress of society, and that the next novelty on the road can be hit by a range of inventors, we should not reward those lucky enough to be the first to hit the novel technological solution. Furthermore, due to the randomness of the system regarding who hits the technological solution first, and who contributed what, it is almost impossible that the reward goes to those who deserve it. In addition, it can be argued that the patent system on average causes more losses than profits even to inventors, as inventors then have to pay for using their ideas when other people have patented them. Especially within complex products and processes it is common to have many contributions from numerous companies. As examples, we can mention new-clear energy, semiconductors, medical appliances, consumer electronics, and domestic appliances, including such as DVD, digital TV, MPEG digital video systems and mobile phones. This means licensing and cross-licensing is a fact of life for electronics. This problem that inventors pay to use their own ideas (assuming that all inventions have a social origin and only one individual or firm gets rewarded), could in principle be solved by rewarding inventors with cash rather than temporary monopolies. This reward system would however not solve the problem surrounding the social origin of inventions where everyone deserves a fair share for their effort, as it is impossible to calculate the effort-share that has been conducted on an individual basis. Basically, the patent system here is viewed as inflicting injury upon others as it is impossible to compensate or pay rewards in proportion to effort conducted and the service provided to society.

\section{Economic incentive rationales: the social benefits from patents}

The rationales for the IPR system here are based upon "political expediency", rather than a natural right argument. It is believed that, by establishing IPRs on ideas, this will create a variety of different "economic incentives" in the behaviour of inventors. Basically, the efficiency of an incentive system is that it drives people to do things they would not otherwise have done, and these incentives will thus result in some benefit to society as a whole. This endorsement of the social benefits of IPRs on technological inventions is the one that has become generally accepted. 
3.1. Incentives to invent, be creative and innovate, as well as motivating the direction of such

The basic proposition of some classical economists, ${ }^{10}$ including Jeremy Bentham, Adam Smith, Jean-Baptiste Say, John Stuart Mill and John Bates Clark, is that, as IPRs provide "the prospect of reward", this in turn encourages creative and technological advance by providing increased incentives to invent, and invest in, and further develop new ideas. In fact, it has been argued that the striving towards temporary monopolies in industry is the most effective stimulus to technological progress, so the granting of temporary monopolies to inventors are necessity in society and that without such the invention inducement would be weakened.

However, the "patent-induced incentives to invent" rationale rests on two assertions: (i) Not enough inventions will be made without effective incentives: neither invention nor exploitation of inventions will take place unless inventors and capitalists believe they will yield profits which make it worth their while to make their efforts and risk their money, and (ii) IPRs are the cheapest and most effective way for society to hold out these incentives.

Along similar lines, it has been argued that even if the IPR system is not the most essential ingredient to make people invent and innovate, it helps when it comes to motivating the direction of such. That is, only the inventions with most commercial opportunities will be explored for profit purposes, so in that sense it promotes "useful inventions" (i.e. those that people want). Basically, the classical economists argued that IPR privileges offer prizes to creative minds, in the sense that is arouses the mental powers and gives them a direction.

\section{Controversy:}

While there is agreement that industrial progress is desirable and inventions are necessary for industrial progress, there is less support for the above-mentioned two assertions.

\footnotetext{
${ }^{10}$ Reviewed by a range of writers: see section 1.
} 
3.1.1 Challenging assumption: Not enough inventions will be made without effective incentives

Most significant, other classical economists ${ }^{11}$ including Frank William Taussig (1915) and Arthur Cecil Pigou (1920) argued that patent rights are superfluous and unnecessary. The basic argument is that inventions happen without patents as it is inborn from childhood and often accidental. Therefore, the patent system, as an incentive mechanism, will not increase inventive activity. However, as argued in 2.2. The natural right to compensation and reward, in section 2, inventions are generally not accidental and scientists must specialise. Furthermore, even to develop a new software programme takes three hundred years in terms of person hours worked (see IBM's statement cited in 1.2. Why the patent content, section 1).

Arrow (1962) argued that although property rights in ideas are clearly useful when it comes to stimulating inventive activity, they are nonetheless inferior to direct government investment in inventive activities. His argument was that even under patent law basic research is bound to be under-rewarded. ${ }^{12}$ Kenneth Arrow basically gave three reasons why patents under-reward the inventor and therefore do not stimulate inventive activity. They were: "uncertainty", "indivisibility" and "appropriability":

Firstly, producing an invention is associated with a great deal of "uncertainty". Kenneth Arrow argues that for any given set of inputs in commodity production the firm knows the output or, at least, the risk factors are pretty certain, so the firm can chose the inputs so as to maximise profits. However, invention production is inherently uncertain in the sense that the inventor cannot calculate the risk as in many other risk-bearing or spreading activities. Basically, invention is more uncertain than the weather, as with modern technology you can at least predict the weather in the short run, even if you cannot control it. With inventions you cannot even predict probability or risk in the short run, nor can you control the outcome. Hence, for the risk-averse,

\footnotetext{
11 Reviewed by a range of writers: see section 1.

12 This view shall be seen to be in sharp contrast to the "social origin of inventions" - argument where the patent system is inefficient because it over-rewards the patentee, resulting in a variety of individual and social costs. See sub-section below on 3.1.2. Challenging assumption: IPRs are the cheapest and most effective way for society to create these incentives.
} 
Kenneth Arrow argues that the patent system will not create optimal inventive effort, but under-investment, in comparison to government investment in inventive activities.

Secondly, there is the problem that ideas or information are by definition "indivisible" commodities. The basic argument is that although Kenneth Arrow in principle agrees with the transaction cost argument that the only way to trade or share ideas or information is by protecting it by a property right, he still argues that such an IPR is inefficient because the inventor is loosing control of its use. Once the idea is shared or sold there is no need for the user of the idea to come back for more. That is, the use of the idea is infinite and it never faces decreasing returns to scale or is used up, so the nature of sharing or trading ideas on the market is very different from other intermediates or commodities. Use of ideas does not depend on the rate of production as with other intermediates, such as e.g. oil. In that sense, even if the seller or inventor retains some intellectual property rights, they still loose control of the idea for all-time exploration and exploitation purposes. Although this argument can also be applied to knowledge embodied in intangible digital products, it should be emphasised that the product cycles within electronics and software and communications are generally very short so consumers need to return to the market again for new products or updating of old products. As the user-interfaces with these products (e.g. software programs) usually involved "learning" (see section 4) the consumers tend to update products rather than chose new types, so it can be argued that the inventor does not necessarily lose control over the consumer of ideas in the knowledge-based economy.

Also, in a completely different type of indivisibility argument put forward by Plant (1934), it can be argued that, although inventions are socially constructed from a bundle of cumulated past and current ideas, the patent is granted on the ground of the full invention. That is, marginal patents do not exist, but the person who hits the right note at the right time gets the full monopoly reward on the particular invention, and the rest participating in the social activity of inventing are left out. It could also be speculated that this lottery version of the patent system might lead to under-investment in inventive activity for the risk averse. It is interesting to see here, how Kenneth Arrow focuses on how the IPR system under-rewards the one who has been 
granted the patent right, while Arnold Plant focuses on how the IPR system over-rewards the patentee.

Both indivisibility problems regarding the intangible nature of ideas (cf. Kenneth Arrow), and the social nature of the origin of ideas (cf. Arnold Plant), can also be considered as "appropriability" problems. This is the third type of setback of the IPR system which Kenneth Arrow explicitly mentions. Other appropriability problems are that the owner of the idea may not be able to exploit it as effectively as others, and due to uncertainty this risk is unknown, so the risk averse may decide against making the idea. Furthermore, not all inventive efforts are easy to appropriate from, even if protected by intellectual property. E.g. with positive externalities society also benefits from inventive activity, and as all benefit does not go exclusively to the inventor, the inventor may feel under-rewarded. Also, a patent does not prevent anyone from thinking about the patented idea, and through pure inspiration produce a different competitive product not embodying or rewarding the original idea. According to Arrow these phenomena have negative implications for the inventive "incentive rationale" for patents. Arrow argues that inventors might prefer to keep secret their inventions (as opposed to patent them), as once the idea is told anyone else can benefit. Especially with products that can only become a commodity by issuing an IPR, as is the case with many digital products and processes (e.g. software, music computer games, business methods, etc.), appropriability problems become severe. With the introduction of the home PC, developments in digital recording and playback techniques, and the use of the Internet as transmitter and content holder, the enforcement of royalty collection in IPR-based digital material has proved difficult and in some instances impossible.

Appropriability problems for the inventor also includes the problems of transaction costs in the marketing and licensing of ideas, intellectual property rights enforcement, portfolio managing of ideas, etc. Such costs shall not be underestimated when investigating problems of incentives. Another cost argument is that, as inventions along trajectories are cumulative, path dependent and complex, in the sense that each invention relies on other past or current inventions, the patent system increases the costs for most subscribers to the system. That is, although development rights are free of 
royalties, the subsequent production and trade rights embodying the ideas are not free, and as there is no point in developing ideas if you cannot use them or control their use, the development and production-rights are intertwined in reality. Thus, the technological interrelatedness of inventions might result in under-investment in inventive activity if ideas are protected by intellectual property.

Finally, it should be noted that in reality most inventors are employed by a manufacturer or capitalist, or they find themselves in a bargaining situation where they have no option but to sell their patents or copyrights at a price below their value. These bargaining situations or conflicts regarding appropriability goes against the reward system idea, both in terms of the human rights issues discussed in a previous section and in terms of the idea of creating special incentives to invent. Thus, Machlup \& Penrose (1950) argued "If the inventors could not hope to reap the fruits of their work, ... another theory could be substituted for the weakened theory of the patent as an incentive to invent: a theory of the patent as an incentive to venture capital for the financing of the development and pioneer exploitation of inventions". Basically, it is less risky to finance the implementation of an idea into products for markets if the idea is covered by an intellectual property. The function of the patent as a stimulus to the inventor's financier should be given more emphasis. The bargaining system and the role of the inventor's financier is central to many industries, but perhaps most well known in the music industry with respect to the power of the record companies, which however might diminish in the digital economy in favour of organised digital publishers.

\subsubsection{Challenging assumption: IPRs are the cheapest and most effective way for society to create these incentives}

The innovation incentives argument is based upon the idea that the IPR system costs nothing or only impose trivial costs. In that sense society gets something for almost nothing. However, a range of other thinkers, including Plant (1934), argue that heavy social costs are unavoidable. That is, even if you achieve certain ends from the IPR system, there also are certain costs which are not insignificant. Social costs include several subject matters, as follows: 
(a) The opportunity cost of investment in arbitrary technological trajectories: Diversion of activity caused by the patent reward system can be into less productive channels. The diversion could be from inventing in one field of research into other less productive pursuits, just because patent protection can more easily be obtained or to a higher extent be enjoyed in that field. Especially Plant (1934) put forward the argument that the patent system provides specific favourable conditions for certain types of inventions and thereby divides the activities in society into arbitrary solutions. Thus, technological trajectories will become arbitrary. Hence, although Arnold Plant agrees with the rationale that patents to a certain extent stimulate inventive activity, he still argues that on balance they are inefficient and cause harm to society. Within corporate strategic management it has also been argued by Rivette \& Kline (2000) that research and development $(\mathrm{R} \& \mathrm{D})$ and branding tend to be pursued in those areas in which patents can help to establish a market share. These are not necessarily the "best" product or process innovations. The strength of the potential patent position is a leading factor in deciding what research to pursue. ${ }^{13}$

(b) Administration and enforcement costs: Bureaucracy concerning administrating and enforcing the IPR system includes costs of court personnel, lawyers, IPR portfolio managers, others engaged in patent applications and litigations, royalty management, etc.

(c) The monopoly or anti-competition costs of "blocking patents"/Setting territories: The extension of monopoly power over individual firms often goes way beyond the scope of an individual patent. The issue of strategic patent blocking put forward by Rivette \& Kline (2000) becomes relevant here. Basically, since the strength of the potential patent position is an important factor in deciding what research to pursue, it is important to consider how patent positions are strategically established. Building a wall of patents around category-leading products can help companies defend against imitators and can secure market share. An example of the importance of patent walls around technological webs is in the strategies of firms. Firms are afraid of specializing too narrowly. Many

\footnotetext{
${ }^{13}$ Kevin Rivette and David Kline gave a couple of examples of this. First, the bio-tech firm Genetics Institute decides which versions of a drug to develop partly on the best results in clinical trials but also according to which version can command the strongest patent protection. And secondly, Gillette's sensor shaver was developed from mapping out the patent landscape for seven variations of the shaver. Examining the strengths and weaknesses of the patent positions for each design compared with the potential rivals, the shaver that the competitors would have the most difficulty trying to simulate was chosen (twenty two patents were thus formed as part of "the patent wall").
} 
firms adopt the policy of always being at "all platforms". It is important to be (i) a part of setting standards in controlling ways of delivering and receiving and consuming software or digital based content (here hardware in relation to broadcast and electronic technologies is central), just as it is important to be (ii) good in its main activity of software or digital content development. That is, IPRs on content (e.g. software, music, computer games, films, business methods) and IPRs on the ways of exchanging the content are equally important. Firms wish to control IPRs on content as well as the pipes (broadcasting, internet, intranet, other networks, etc.) in which the content flows or is used. This is so in particular within media services in which "content" and "broadcasting" mergers take place for such reasons. Thus, in the micro-electronic world in which value is mainly created via royalties from the "flow" of software and/or digital based content, it is important for firms to be able to control this flow and not be dependent on other service providers. Firms therefore patent hardware technologies to protect the way in which they can profit from their software or digital technologies.

Patent walls can be used to impose threats of patent infringement suits to block potential rivals. This is an increasingly common practice. The money currently paid to IPR lawyers is unprecedented, as IPRs protect the key competitive strategic asset (or intellectual capital) of many firms. It is not uncommon for smaller firms to have insufficient funds to go to court, so when major firms come after them, they withdraw or make other special arrangements with the company claiming infringement. Building a patent wall around the product or process is not the only way to hold back competitors. If your competitor has patented an invention, but has not patented the surrounding application-innovations, a corporate strategy can be to patent these, so your competitor is locked out of further developing the market, or is at least totally dependent on you. This is the essence of bracketing. It should not need to be explained that such forms of patent blocking reduces competition and hence social welfare.

Owning IPRs lets companies develop favourable partnerships and licensing relationships. For example, strategic collateral licensing agreements between parties may provide firms with lower cost components. Rivette \& Kline (2000) explained how Dell avoids paying IBM millions of dollars in 
royalties through such an agreement, making Dell more price competitive. Yet, as one firm is not powerful enough to set standards alone, and to avoid the existence of mandatory standards, cross-licensing has often been the solution. MPEG-LA (with many major firms collaborating around setting the standards in digital video systems) is a good example. Such collaboration is around common patent pools to which they all file their relevant patents. In that way firms share ideas, set common standards, and royalties are shared on the basis of the contribution from the firms involved. Patent pools can be based upon strategic choice of partners, or it can be based upon an open architecture, as is the case of mobile phones operating systems. In an open-source architecture anyone who can contribute to the pool can join and use or license the intellectual capital in the IPR pool. In March 2002 Nokia $^{15}$ argued that an open-source patent pool architecture is not made only to enhance common standards, but also to avoid Microsoft situations where the winner takes all. However, when it comes to sharing the royalties in more closed architecture patent pools, accountability and bargaining power does play a role. A good example is the music industry, as mentioned in a previous section. Strategic licensing markets are still in their infancy, but waiting for the big boom.

(d) Opportunity costs in depriving others of using the most efficient solution: However beneficial the patent may be for the inventor who receives the privilege, the community will not automatically be benefited from an idea if it is protected by an IPR, and this in turn deprives society of the benefits that would flow from the more widespread use of these ideas. Thus, temporary prevention of the use of the most efficient processes by most other producers can be considered as a social cost.

(e) Opportunity costs of depriving inventors of what they had before (assuming invention is a social process): Assuming that invention is a social or collective process to which many contribute, the opponents of the patent system argue that a patent or copyright deprives others of what they had before (e.g. the opportunity to use the same idea that the patentee now owns). This in turn also deprives society of the benefits that would flow from the more widespread use of these ideas.

${ }^{15}$ At a Customer Relationship Management workshop in Espoo, Finland. 
(f) The cost of patent races: As argued in section 1, the patent system can be compared to a lottery in the sense that most inventive activity is a social process, yet those who win (i.e. hit the right notes at the right time) get the monopoly while the rest are precluded. This might be one of the reasons for patent races, rather than sensible patenting strategies, despite being very financial resource consuming. Another reason for patent races is also the fear that competitors will be establishing patent walls or do bracketing, so you try to patent everything yourself as fast as possible. The firms inventing in the area of broadcasting and satellite systems have ${ }^{16}$ expressed concern regarding the huge resource costs involved with such patent races, that are triggered mainly to protect against constant threats for infringement cases or problems regarding being locked-out of the development trajectory.

\subsection{Incentive to use and allocate resources more efficiently}

When understanding the economics of IPR law Posner (1992) focuses on the static and dynamic effects with respect to resource allocation.

The static effects basically read: without property rights resources will be over-used or exhausted as none takes the costs imposed on other into account. E.g. if none has the right to exclude other from using a piece of land all farmers will put their cows there to graze. At a certain stage this will impose costs on the other farmers. The more cows on the land, the more they will need to graze in order to eat the same amount of grass. This will reduce their weight in addition to exhausting the field, and this is inefficient. ${ }^{17}$ By privatizing the land, in the sense that each farmer owns a share, the land will be used more efficiently, as the farmers will include the costs each additional cow will impose to the system. By making the rights transferable, the farmers that can use the resources most efficiently will end up using or owning most of the land, as it makes sense for the less efficient farmers rent the land or sell. Hence, it should follow that with intellectual property rights, ideas are used or owned by the most efficient entrepreneurs.

Furthermore, the dynamic resource allocation rationale for IPR, suggested by Richard Posner, reads: If all property rights on land were abolished so that a

\footnotetext{
16 In interviews to the EU fifth framework project ("Patents and services"; contract no ERBHPV2-CT-1999-06).

17 Notice analogy to highway congestion.
} 
farmer owned neither the land nor the crop, the farmer has no legal remedy against another who reaps it. Hence, in such circumstances, the society will shift to other methods of subsistence (such as hunting) as it involves less preparatory investment. In the same way, in a world without patents where anyone is free to use others' ideas, inventive activity would be biased towards inventions that could be held secret, as well as biased towards activities that involve minimum preparatory investment. While an implication here is that the investor and inventor is not encouraged to conduct his activities as he will not be able to recover costs of investment (i.e. pricing at marginal production costs means that firms do not recover $\mathrm{R} \& \mathrm{D}$ costs) or expect any reward, the main dynamic point here is that legal protection of property rights creates incentives to use resources more efficiently through investment in planning and development of resources.

Basically, the case for recognizing and protecting rights in productive knowledge rests on the assumption that resources for advancing knowledge are scarce. Firstly, without property rights on productive knowledge, it is argued that effort will be directed toward activities where rent can be appropriated more easily. Secondly, the resources that are finally devoted towards knowledge creation will be used more efficiently if the knowledge output is protected by an IPR. This is because of inventors' drive to maximise the economic reward from IPR-protected inventions, in which innovation-enhanced competition encourages inventors to come up with the most competitive product or process that uses resources most efficiently, or hold a desired new attribute, or both.

\section{Controversy:}

A standard static efficiency argument against the IPR system is that it increases the price for the consumer and therefore reduces welfare. That is, under neoclassical theory the marginal cost of production is equivalent to the price of production $(\mathrm{MC}=\mathrm{P})$. However, as the manufacturer also has to pay royalties " $\mathrm{R}$ " to the inventor of the product, the price of the good exceeds marginal costs $(\mathrm{MC}+\mathrm{R}=\mathrm{P})$. This would at first hand seem inefficient and decreasing social welfare. However, the system believers argue that " $R$ " necessarily reflects the costs of having a property right system enforcing more efficient 
allocation of resources (just as the costs of having a fence between two farmers separating their animals). But, the answer from the system disbelievers here would naturally be that the social costs often goes far beyond " $R$ " that is treated as a trivial cost. A full list of social costs of the system was discussed in the sub-section 3.1.2 Challenging assumption: IPRs are the cheapest and most effective way for society to create these incentives, above .

More radically, Plant (1934) argued that, whereas property rights on land under property law is useful as it creates more efficient use of scarce resources, property rights on ideas are of a very different nature. Arnold Plant argued that IPRs are not the consequence of scarce resources as in the property rights on land case, but they are the deliberate creation of a statute, that creates scarcity. In that sense intellectual property law cannot be compared with land property law. Arnold Plant goes on to comment on the social costs of making ideas scarce, which he believes causes more non-optimal or inefficient use of resources.

Paul David also argues that fences in knowledge-based sectors have quite different consequences than fences for livestock. E.g. David (2001) argued in his report "Will building "good fences" really make "good neighbours" in science?" to the European Commission (DG-Research) that, fences in the information spaces (especially within scientific communities) shall not be confused with fences for livestock from neighbouring farms. The nature of the two subjects is very different. It is agreed that fences separating livestock from neighbouring farms is efficient as such will prevent the animals to wander to graze and thereby destroy the provender of the animals already pasturing there. However, Paul David argues that information spaces in scientific communities are not subject to being "over-grazed" but, instead are likely to be enriched and rendered more accurate, and more fully documented the more researchers are allowed to crumb through the ideas and information feeding into science. Paul David argues that it is through wide and complete disclosure and the sceptical efforts to replicate novel research findings, that scientific communities build bodies of reliable knowledge. His report was written to promote greater awareness for the European Commission (DGResearch) regarding the benefits of collaborative scientific research in general and Internet-based collaborations in particular. 
Winter (1993) argued that although it might be true that patents lead to more innovative effort, from a social welfare point of view, the IPR system does not necessarily lead to more efficient allocation of resources. He argued that inefficiencies might occur if patents are granted to inventors at an early stage of a technological trajectory. When a new trajectory is still being explored by a variety of inventors, an early granting of patents might disrupt and deprive the free exploration phase, and we might be diverted in an inefficient direction. Furthermore, the need for an inventor to avoid a technological region occupied by a patent holder will increase the cost of making a new economically comparable invention. From a technological and economic point of view, this might result in inefficient technological trajectories. Also, a system with strong IPR protection may result in more resources devoted to expensive inventive and innovative $\mathrm{R} \& \mathrm{D}$ effort (in order to avoid a technological region occupied by a patent holder) rather than more cheap imitative effort. Hence, Sidney Winter argued how resources allocated to inventive activity might be allocated inefficiently or sub-optimally under an IPR regime (see section 5 for further discussion). However, the system believer would argue that patents are granted early (i.e. before invention has been carried to the point of commercial feasibility) in order to head off costly duplication of expensive development work (see section 5).

Arthur (1988; 1996) argued that in industries where the fixed set-up costs are high in comparison to the cost of reproduction, individuals and organizations have a strong incentive to identify and stick with a single option, which in turn will lead to inefficient allocation of resources. This is certainly the case for knowledge and information-based products and processes. The basic argument is that, from a technological trajectory point of view, high fixed set-up costs create a high pay-off for further investments in a given technology, especially if the marginal costs of reproduction are small as in digital products. Bill Gates argues that with intellectual property, the upfront costs are what it's all about: "Say a piece of software costs $\$ 10$ million to create and the marginal costs, because it's going to be distributed electronically, are basically zero". Once the costs of development have been recouped, "every single additional unit is pure profit" (Wall Street Journal, August 23 in 2001). Such increasing returns to scale also make it difficult for other firms to enter the market, even if their technologies or 
ideas are superior, as they start at smaller scale and higher unit costs of production. ${ }^{18}$ Thus, in this fashion, IPRs may encourage investment in arbitrary or sub-optimal technological trajectories and thereby inefficient use of resources.

Arrow (1962) argues that the patent system results in under-allocation of resources to invention. He argues that under monopolistic situations (even if temporary monopoly as in the patent case), the incentive to innovate will be lower than under competitive conditions. Although monopoly situations will increase appropriability possibilities, Kenneth Arrow argues that this is offset by the disincentives created by the inventor's pre-invention monopoly profits. However, even under competitive conditions allocation of resources to invention will still be less than socially desirable due to uncertainty, indivisibility and appropriability problems (see previous section 3.1. Incentives to invent be creative and innovate, as well as motivating the direction of such). To solve this allocation problem, Kenneth Arrow argues for government involvement and government expenditures, and he even suggests thinking about alternative methods of compensation and reward systems. The problem is just how much to allocate to inventive activity, as uncertainty will always be there. However, David \& Olsen (1992) argue that Kenneth Arrow's argument on "loss from monopolies" rests on the assumption that the monopolist is actively using his patented idea, but that this is only the case for a short or brief period. Paul David and Trond Olsen argue that the information spill-over from IPRs is the overruling rationale, and that this is indeed welfare enhancing (see section 5 for discussion).

\section{Increased competition and "market protection of entrepreneurial talent" rationales: industrial development from patents}

The rationale of enhanced competition and the "market protection of entrepreneurial talent" rationale can also be regarded as "political expediency". Here it is believed that, by establishing IPRs on ideas, this will create industrial development and social welfare through enhanced competition or through market protection.

\footnotetext{
${ }^{18}$ By moving to larger production runs, fixed costs can be spread over more output, leading to lower unit costs of production which in its turn spill over to lower prices. This makes the technology more attractive and more will adopt it, leading to even lower unit costs and prices, and so forth.
} 
4.1. The innovation enhanced competition and "nature of ideas" argument

The fact that knowledge can be consumed jointly, and can be reproduced very cheaply means that it has some of the qualities of a public good (usually referred to as the "expansible" or "non-rival" aspect of a public good). But, unlike a public good, it is possible for the creator of an idea to exclude others from using it in production and trade, by use of an IPR. This rival aspect of ideas embodied in production and trade of goods and services is believed to stimulate innovation-enhanced competition, by providing incentives to innovate in using scarce resources more efficiently or inventing the next new thing. Thus, IPRs are here believed to stimulate a competitive dynamic environment as well as to strengthen and broaden continuous innovators.

\section{Controversy:}

The arguments here rest on the assertion that IPRs are the best way to stimulate competition. Obviously it is debatable whether society experiences more competition by creating temporary monopolies. The whole argument of corporate strategies surrounding IPRs and strategic patent blocking becomes relevant here.

Whereas Kenneth Arrow argues (1962) that patent grants lack sufficient blocking power for the inventors who cannot fully appropriate from their idea (see above sections 3 and 4) so there is too little rivalry; others, such as Plant (1934), argue that patent monopolies provide such extreme privileges and appropriation opportunities to the inventor against other producers and even the consumers (see above section 4) so rivalry becomes reckless. Both cases are competition distorting. Along similar lines as Arnold Plant, Merges \& Nelson (1990) argued that inventive rivalry is good for inventive progress, but that too strong IPR protection will distort such progress due to patent blocking slowing down cumulativeness. The basic argument is that, most innovations take place in a social context, in the sense that complex and multi-component products are the norm in many industries, and individual patents often cover only a single component or sub-component. Basically, there is no simple "one to one" mapping of products and property rights, but each product includes a variety 
of IPRs of different types and with different scopes and durations. The breath of the patent scope is very important for understanding the monopoly effects of the patent system. Due to cumulativeness in the innovative processes, a more narrow protection favours secondary inventions, but sacrifices the economic incentives that otherwise would be offered for breakthrough inventions, whereas broad protection has the opposite effect (as knowledge has become scarce and costly for secondary inventions). What is the optimal length and what is the optimal breath of patent protection in a cumulative innovation process is difficult to say. Robert Merges and Richard Nelson illustrated how history has shown that strengthening IPR protection will not increase invention, due to the increased costs of the patent scope. Arguing that IPRs do help to reach certain ends, Robert Merges and Richard Nelson discuss the idea of compulsory licensing to enhance more inventive rivalry.

When discussing patent blocking, we need to consider what the patent protects and what it does not protect. Development rights (i.e. the right to use the idea to develop another idea) are not directly protected. However, production and trade rights (i.e. the right to use the idea to produce and trade a commodity) is protected through a patent. However, it could be argued that the development rights are indirectly protected by the production and trade rights, as there is no point in developing an idea if you cannot use it for commercial purposes. Cheung (1986) argued in the volume edited by Palmer that the exclusive rights to produce and trade a product also imply exclusive rights to improve a patented idea. "In short, the rule for improvement would seem to read: You may tinker with my patent any way you please, but plan to pay me when you produce any commodity over which I have some claim; moreover, to avoid my possible excessive demands, it may be wise for you to obtain a license from me in advance". Hence, a patent does imply some exclusive rights on development to the extent that the improvement is dominated by the original invention. Hence, patent blocking here is argued to destroy competition. This is also why "pure ideas" - i.e. laws of nature (physics laws), theoretical principles (e.g. some mathematics), and natural species - are not normally eligible for patent protection (an exception being the controversial right to patent gene-codes in some regions of the world). Patenting such pure ideas would block innovation and competition and thereby also block progress for industrial development and social welfare. 
However, blocking power aimed to diminish competition is often reached by corporate strategic behaviour surrounding patenting. Blocking actions are channelled through patent assignments (i.e. outright transaction or transfer/ sale of rights) or cross-licensing and patent pooling (i.e. each participant contributes some to the development trajectory on a royalty free basis). Such blocking actions are also often used to produce immunity from litigation because of the high (and increasing) costs of infringement suits. Thus, the value of patents essentially depends on its blocking power. Therefore, as highlighted in section 3, when making investment decisions, firms lay out their patent portfolios when deciding which products to commercialize and which technological trajectories to participate in. It is essentially about positioning, but signalling is also important in this game.

The historical evidence cited by David (1985) and Arthur (1988, 1996) suggest various circumstances that make a technological idea prone to increasing returns and lock-in and therefore competition distorting. Below it will be argued how such effects are reinforced in the intangible economy where wealth is often generated through knowledge-based intangible products and processes such as software and computer implemented inventions (e.g. business methods, computer games, etc.). Although Paul David and Brian Arthur emphasized how lock-in can occur from random events, this article considers how IPRs can enforce such lock-in mechanisms. Basically, as IPRs on a locked-in idea generates profit over time, this encourages corporate strategies to take advantage of such increasing returns dynamics to generate lock-in situations. The basic argument is that the dynamics of the electronic sector and the power of IPR strategies and positioning have implications for the value of IPRs, so it encourages anti-competitive behaviour and enforces monopoly markets. The arguments comprise:

(a) Learning effects and increasing returns to adoption: In the world of increasing returns to adoption as within micro-electronic knowledge-based products and processes, it is often the learning effects (learning by doing, learning by using, etc.) that explain lock-in dynamics. A key point is the quasiirreversibility of investments in which the cost of software conversion increases over time due to increased learning of the specific skills and habituation, while 
the costs of hardware conversion decreases in the sense that it is easier to make hardware types become compatible with other and new systems, than to retrain people to use new software. The well-known example researched by David (1985) is our steady use of the 125 years old QWERTY key-board, as opposed to the Dvorak Specific Keyboard which in principle allows an experienced typist to type $20-40 \%$ faster. A more recent example comes from IBM who explained ${ }^{19}$ how (against their initial anticipation) their software patents last longer than hardware patents, possibly due to the importance of habitation and learning effects of the consumers of their software products. Basically, in order to increase customer bonding (or customer loyalty) firms today deliberately differentiate user-interfaces in order to transfer specific skills to the end-user. This strategy is adapted in on-line supermarket shopping, on-line banking and also with respect to mobile phones.

Another aspect of the learning effects is that, learning gained in the operation of micro-electronic knowledge-based complex products and processes also leads to higher returns from continuing use. With repetition, individuals learn how to use products more effectively, and especially during interactive learning (as with micro-electronic products or processes) customers' learning paths and experiences are likely to spur further innovations in the same product or in related activities. In that sense our knowledge gets locked into trajectories; we develop or use what we know about, and we know about what we develop and use. It is impossible to change path or advance in areas in which we have no invested pre-knowledge, and this has huge implications for the value of IPRs in fundamental inventions.

The bottom line here is that technological trajectories in software and software implemented business methods are enviable even without IPRs due to learning effects. Indeed, this kind of "pure learning" effect of the firms' intellectual capital is interesting as the invention is informally protected even without the formal legal framework. Hence, in this context IPRs serve mostly as a mean by which knowledge embodied in software and some computer implemented inventions can be exploited for excessive rent creation. Therefore, one should reconsider how legitimate the market protection rationale of the IPR system is in relation to the learning-based micro-electronic innovation systems.

\footnotetext{
${ }^{19}$ In a meeting regarding the harmonization of the EU's policy on computer implemented inventions in the Danish parliament, February 2002.
} 
(b) Network externalities and technological webs: Network externalities occur when the benefits an individual receives from a particular activity increase as others adopt the same option. This enhanced appeal attracts more users, reinforcing the existing advantage, and so forth. Network externalities are especially significant when a technology is compatible with a linked infrastructure. VHS versus Betamax is the text-book example: Video technology VHS basically won over the Betamax video recorder system due to the greater availability and variety of VHS recorded products. In the new economy of micro-electronic networks, the network externalities are enormous and reaches throughout social and corporate networks. Furthermore, technologies generally do not exist in isolation but in an entire complex network of different technologies. The message here put forward by Brian Arthur is to build technological webs. ${ }^{20}$ In this respect, lock-in to certain institutional and technological trajectories is enhanced if they are coordinated or "fit" with activities of other institutions or technologies and their development. Software is compatible with hardware, ICT systems, organisational structures of business and social relationships as well as other standards. Hence, micro-electronic technological trajectories do not merely survive because of their technological properties, but because they are embedded in an institutional set-up of an economic or social system. The bottom line is that the value from IPRs are enhanced if they are coordinated or "fit" with an infrastructure.

In this context IPRs can serve as a mean by which knowledge embodied in software and other micro-electronic products and processes can be exploited after lock-in. Also, collaboration around IPRs can serve as a means by which standards in software and other micro-electronics are set, appropriated and exploited. The creation of closed architecture "patent pools" or cross-licensing in which firms share knowledge, and thereby trajectory of development, is an example on how firms collaborate around setting technological standards and jointly contribute to lock-in and subsequent exploitation.

(c) Informational increasing returns to adoption: Individuals may feel a need to "pick the right horse" because options that fail to win broad acceptance will have drawbacks later on. In that sense Brian Arthur argues how network

\footnotetext{
20 This is what IBM did in the 1980s when their technological trajectory of the DOS based system won over Apple's Macintosh based computer systems. IBM allowed technological clones, as it found it difficult to create lock-in on its own.
} 
externalities derive from the self-fulfilling character of expectations. More generally, a technology that is widely adopted enjoys the advantage of being better known and better understood. For the risk averse, adopting it becomes attractive. Thus, projections about future aggregate use patterns lead individuals and corporations to adapt their actions in ways that help to make those expectations come true. In this context we adapt our actions in the light of our expectations about the actions of others. The fast adoption (through information and communication technology) by individuals and corporations of some of the new micro-electronic products and processes has surely been a result of some of this dynamism, and this has influenced forceful technological trajectories in the new electronic era. Given such dynamics, unjustified rent from IPRs obtained from informational increasing returns may have occurred.

(d) Knowledge-based intangibles underpinning increasing returns to scale: As knowledge-based intangible products and processes (such as business methods, electronic products, etc.) enjoy increasing returns to scale (just as the IPR-protected knowledge embodied in products or processes) firms have great incentives to expand markets for such intangible ideas when protected via an IPR. Basically, intangible knowledge-based products and processes such as software, computer games, business methods, etc., can be consumed jointly (just like genuine ideas in knowledge markets), and can be reproduced very cheaply, meaning they have some of the qualities of a public good. The speed by which markets can expand for such products is expected to increase in the electronic age, as the means by which such information based products and processes are reproduced and spread become electronic. Being protected by an IPR may allow market price substantial higher than marginal cost, opening the possibility for unfair exploitation of ideas due to lock-in situations (as explained above) as markets expand. Thus, in 1994 the UK's Monopolies and Mergers Commission (MMC) conducted an enquiry into the music record companies regarding the high price of CDs, although they controversially concluded in favour of the record companies. The basic argument here is that although IPRs may initially cover fixed costs of investment in new ideas, they might subsequently provide a platform for unfair exploitation (by marking price unfairly higher than marginal costs) through lock-in. This in turn also has implications for the existence of sub-optimal or arbitrary technological solutions, as discussed in section 3. 
4.2. The "market protection of entrepreneurial talent" for industrial development rationale

It is proposed that efficient IPR protection allows profit-oriented firms to enter (or develop) an industry or market. This rationale of patents has also been compared to that of tariff protection. Just as with tariffs, a monopoly patent protects market entry and allows a firm to price higher than the marginal cost of production. The idea is that a temporary production and trade privilege will allow a firm or industry to develop and mature, while it is protected against new market entry. Kitch (1977) argued that IPRs allow breathing room for the inventor to invest in development without fear that another firm will steal the idea. Furthermore, the temporary trade privilege in the form of an IPR should, just as with a tariff, help a firm or an industry to cover the fixed costs of inventing and producing a new product. This IPR rationale rests on the assumption that such temporary production and trade privilege is the best ground for entrepreneurial talent to enter markets and cause industrial development and progress.

\section{Controversy:}

Comparing patent protection with tariff protection and comparing patent monopolies with monopoly privileges in general tend to help patent opponents and weaken patent defenders. Against patent protection during the final shaping of the patent system in the nineteenth century was the free trade argument. Basically, those for tariffs were for patents. It was argued that IPRs are important for entrepreneurial talent to create and develop a market (just as the function of tariffs for firms and industries). Those against tariffs were also generally against patents.

However, Jeremy Benthan who was an advocate of patent protection argued that the exclusive privilege given to inventors has nothing in common with general monopolies which are so justly decried. Along similar lines, Adam Smith argued that although monopolies in trade deranged the more or less natural distribution of stock in society and were therefore hurtful to society, a temporary monopoly granted to an inventor of a new machine 
could be justified as a means of rewarding risk and expense and thereby encourage new ventures.

\section{Economic rationale of organizing science, technology and creativity: Increased information spill-over}

In order to secure a stream of inventions and innovations it is important that new ideas become generally known to society. The argument is that, in the absence of protecting novel ideas the inventors will keep their inventions secret and they will die with them. Hence, it is in the interest of society to induce the inventors to disclose their secret for the use of future generations of inventors. It is proposed that this can best be done by granting exclusive rights to the inventors for their innovation in terms of efficient IPR protection. Such exclusive rights can be regarded as a contract the inventor gets from government if the inventor agrees to disclose the idea in question (see (a) Negotiated incentive to disclose ideas in libraries, below). As the nature of an idea or information good is non-rival, such exclusive rights will also help the inventor to directly exploit, or appropriate from, the idea as a value driven intellectual capital, which in its turn will provide an incentive to share the idea (see (b) Incentive to disclose ideas in trade, below).

The information spill-over effects from patents has also been taken seriously in the formal-modelling neoclassical economic literature. Rivera-Batiz \& Romer (1991) built upon Arrow's (1962) notion of perfect knowledge spillover once ideas are disclosed in a patent document (as owners of ideas thereby have lost control of appropriation from such ideas). It can be said that Luis Rivera-Batiz and Paul Romer thereby considered the communication rationale of the patent system. Basically, they incorporated perfect knowledge spill-over and knowledge accumulation from patents directly into an endogenous growth model: "Holders of patents on previous designs have no technological or legal means of preventing designers of new goods from using the ideas implicit in the existing designs. The stock of A [knowledge or ideas] that can be put to use, with no compensation, by any individual researcher is therefore the entire stock of knowledge about the previous designs, provided that there exists a communication network that makes this information available". (However, 
although an IPR does not involve any research and development right, Luis Rivera-Batiz and Paul Romer did not envisage a problem that the production and trade rights also have knock-on effects on the research and development right. Basically, what is the point in developing if you cannot exploit your idea, — so the spill-over may not be so perfect after all (see section 3 for discussion).

Hence, the rationale is that patent rights should help to facilitate the world-wide sharing of ideas, creative efforts, and new technologies nationally and world-wide. It is believed that this creates faster knowledge spill-over and a more coherent technological and industrial development, which in turn will strengthen the national or global economy. Thus the IPR rationale for increased information spill-over can be regarded as a "political expediency" rationale.

\section{1. "Incentives to disclose ideas" rationale}

The "incentives to disclose ideas" rationale is about incentives to disclose ideas in libraries and incentives to disclose ideas in trade:

(a) Negotiated incentive to disclose ideas in libraries: Patents provide immediate information to rivals who can incorporate such into their own knowledge bases even though they cannot make direct commercial use of it. The rationale here is that patents are necessary as incentives to induce inventors to disclose their new inventions instead of keeping them secret. That is, perhaps there would be enough incentive to invent without patents, but they would not be disclosed due to the inventor not wishing to loose control of the idea. Hence, by issuing patents protecting the inventions, inventors agree to disclose their inventions that thus become part of society's knowledge base. To avoid interpretation of patents as "privileges" this argument has been developed as part of "social contact theory". In this statute a patent is not regarded as a privilege granted by society, but a bargain between society and the inventor. Basically it is an exclusive right or contract the inventor gets if she agrees to disclose a novel idea.

(b) Incentive to disclose ideas in trade: Secondly, a rationale is that patents provide direct incentives for sharing productive ideas through trade in the 
sense that knowledge, by definition, faces increasing returns to scale. It can be argued that although knowledge is not a new feature of capitalist production, it is taking on a greater weight in the globalizing economy when protected by an IPR. Assessing this trend is complemented by the economic nature of knowledge or ideas themselves. The fact that knowledge can be consumed jointly, and can be reproduced very cheaply means that it has some of the qualities of a public good (usually referred to as the "expansible" or "non-rival" aspect of a public good). But, unlike a public good, it is possible for the creator of an idea to exclude others from using it by use of patent rights, opening the possibility for wider commercial exploitation. As argued by Luis RiveraBatiz and Paul Romer, establishing property rights for ideas means a market price higher than its marginal cost, which tends to zero, giving rise to rents. This in turn implies an incessant incentive or drive to expand the market for ideas so as to generate greater rents. In this context, IPRs are in principle able to create a market for knowledge, and as ideas face increasing returns to scale by nature, this gives rise to increasing rent or profit as markets expand.

David \& Olsen (1992) discuss how patent monopolies may improve economic welfare when there is learning externalities or spill-over. The basic argument is that patents improve economic efficiency by speeding up learning by doing and quickening the diffusion of existing innovation. However, Paul David and Trond Olsen do recognize that there are certain costs, as monopolies also impose some disincentive for continuous innovations (cf. Kenneth Arrow's argument in section 3 where the (i) efficiency gains from patents used to account for market failures (i.e. not enough resources will be used on inventive activity in the absence of patent protection), does not outweigh the (ii) loss from monopolies (cf. the view that monopolies impose a dis-incentive for continuous innovations). Yet, Paul David and Trond Olsen commented on how Kenneth Arrow's argument on "loss from monopolies" rested on the assumption that the monopolist was actively using a production process embodying the patented idea or was producing a good embodying the patented idea. Paul David and Trond Olsen argued that this is only the case for a short or brief period, but as competition intensifies this use of the idea would end. However, the monopolist would withhold the patent for licensing purposes. Thus, the function of the long-term rationales for patenting is basically to expand the market for their ideas, and as discussed above this could 
provide a welfare gain to society in terms of learning externalities or spill-over. Paul David and Trond Olsen go on to criticise that the national patent systems require patent holders to pay a significant amount of annual fees and like (even after they stop directly using their patented idea), reflecting the view that patent monopolies are simply imposing a deadweight welfare burden upon the economy.

\section{Controversy:}

However, as discussed by Machlup \& Penrose (1950) there are many (conflicting) objections to such bargain agreements that challenge the information disclosure and spill-over rationales for patent rights:

- If inventors chose to keep inventions secret, society will not lose much because usually similar ideas are developed elsewhere, due to the social or collective nature of inventions.

- It is practically impossible to keep ideas secret so the idea will be revealed even without an IPR. Eager competitors will find a way to find out (e.g. reverse engineering, espionage). This argument resemble the appropriability problem.

- Where an inventor thinks that they will succeed in guarding a secret, they will not take out a patent. Hence, this argument states that patents are only taken out where the secret is difficult to keep or where others develop similar ideas. Hence, there is a net loss in the system since rational inventors would only use the patent system to restrict access to markets, and would not cause disclosure of unique inventions.

- Since patents are only granted at a certain stage of an invention, the patent system encourages secrecy in the development stage. Without patents, inventors would quickly publish their ideas under development to secure recognition and fame. Thus, patent systems encourage secrecy and when patent disclosure finally comes about, it is at a huge social cost in terms of "lost past disclose at the development stage". It might even be argued that if ideas are published before they have developed into patentable inventions, ideas would ripen more quickly and would become available for practical application elsewhere much sooner. 
Winter (1993) focused on the mechanism as well as welfare effects from patent spill-overs to judge the efficiency of the patent system. He questioned whether very short lived patents, or even no patents at all, might in some contexts yield higher economic welfare than the patent rights conferred under existing institutional arrangements. The main claim is that due to the costs of spill-overs increases under patent protection, the patent system can become inefficient. His main point is that invention theories explain invention diffusion from a supply side point of view, and they do not consider the effects of the patent system from the demand side (or invention adoption side): In an evolutionary model Sidney Winter illustrates how patents increase $R \& D$ intensity by more than $20 \%$ (resulting in more inventions and innovations). From a patent advocate point of view, it is of course an aim of the patent system to stimulate more inventions and hence innovations. However, Sidney Winter argues that from a welfare point of view not all those $\mathrm{R} \& \mathrm{D}$ are spent productively. The reason is that the patent system enforces high barriers to imitate (e.g. through high royalty fees or patent blocking), so instead of adopting others' technological solutions, firms prefer to develop their own competitive trajectory. (The rent from the patent depends on how scarce the knowledge is and the benefit it can yield.). Thus, as resources for advancing or using knowledge are scarce and expensive in a patent system, more $R \& D$ are spent on innovative effort. However, R\&D spent on innovative effort is very expensive compared to the less expensive imitative effort, in an absence of a patent system. Furthermore, Sidney Winter argues that this rival based patent system where each firm develops its own competitive trajectory, may result in too many sub-optimal solutions and arbitrary technological trajectories. Thus, Sidney Winter states that best practice productivity levels in most firms tend to be higher in a system without patents. He concludes that 3-year patents are sufficient for some small role for imitation, but longer period would reduce imitation entirely and raise nonoptimal R\&D effort. Today the length of a patent is 20 years in most countries.

Despite the contribution from Winter (1993), it is evident that we know more about how the patent system affects invention and innovation (see sections 3 and 4), than the role it plays in adoption or diffusion of ideas and spill-over. 
5.2. Rationale of uniformity, order, increased information, increased spill-over and better advice

A central "political expediency" rationale of organizing science and technology at the macro level is that an IPR system not only provides economic incentives, but also offers information on new trajectories, structural changes in technological development, and the technological capabilities of firms, industries, sectors and nations. That is, patents granted in specific fields of activity often follow identifiable trajectories or paradigms associated with the use of particular patent classes. An understanding of the trajectories being followed at a particular time may yield qualitative predictions about the nature of the improvements that are likely to be forthcoming in the near future. This information provided through the IPR system allows governments to be more effectively advised on science and technology policy matters. E.g. so far, patent statistics have shown promise and some success in analysing: international patterns of innovative activities in relation to trade and production; patterns of innovative activities amongst firms, and their effects upon competence as well as performance and industrial structure; rates and directions of innovative activities in different technical fields and industrial sectors; and links between science and technology. See e.g. the work by Andersen (2001), the work by Keith Pavitt and Parimal Patel and colleagues at the Science and Technology Policy Research Unit at the University of Sussex, and John Cantwell and colleagues at the University of Reading. Also, a national and international IPR system brings in national and international uniformity in the way the knowledge base is organised into scientific classes, so scope of analysis and comparison increases.

The transparency of systems of organizing knowledge also seeks to promote cross-country trade in IPRs, and hence international integration of science, technology and creative efforts, stimulating prosperity world-wide. Basically, the transaction cost rationale for the IPR system is manifold: (i) A standardised system simplifies contracts in buying and selling knowledge. (ii) It also reduces information asymmetry and increases trust since the full idea is disclosed in a patent document. (iii) The transparency of knowledge helps to prevent the duplication of creative effort and encourages coordination and broadening of activities, allowing inventive resources to be used more efficiently. 
Patents are also granted early (before invention has been carried to the point of commercial feasibility) in order to head off costly duplication of expensive development work. (iv) Through open disclosure, IPRs also provide an informal or formal way of collaborating around technological trajectories. In the context of (iii) and (iv), the efficiency of the IPR system can also be viewed from a transaction cost perspective in which the system reduces inefficiency by reducing information asymmetry.

\section{Controversy:}

No one really objects to the usefulness of the information spill-over rationale for promoting information on science and technology matters, as well as for promoting trade in ideas and standard setting, etc.

\section{Conclusion}

IPR regimes are complex systems, with strong moral rationales, strong economic incentives rationales, increased competition and "market protection of entrepreneurial talent" rationales, and economic rationales for organizing science and technology. However, this article has illustrated that IPR systems are not neutral; they set the rules of the game in which individuals and organisations interact, and in which corporate leaders and stakeholders are shaped and technological trajectories selected or reinforced. The article therefore argues that the rationales and social and economic effects of the IPR system are vital and must be addressed at the political level. What do we wish to achieve from the system (i.e. the rationales) and what are the social and economic effects of the system? Before answering those questions we cannot design patent policy for the twentieth century, or even know if patents is the appropriate policy instrument in the first place. It is a problem that national governments prepare for the knowledge-based electronic age assuming that a tightening of the patent system will provide the answer. There are many rationales and controversies in the above theoretical literature regarding the operation of the IPR system, but we know little about the empirical social and economic effects. However, the efficiency of patent system cannot be taken for granted. This article therefore 
argues that the patent regime should be used cautiously. The controversies surrounding IPRs are not to be solved from philosophy or from exercises in theoretical logics.

The gain from stronger intellectual protection is far from axiomatic. Figure 1 illustrates how innovation policy is designed around some IPR legal regimes. The current tightening of such policy is obviously based upon some visions regarding why this might be the solution for the knowledge-based economy, although the political arena has not consulted the academic literature regarding the rationales behind such policy. However, Figure 1 illustrates that we cannot base our policy on visions alone; the operation of the market economy is crucial, and currently we do not know the social and economic effects in the socio-economy. Speculations on such effects have been discussed in this article.

FIGURE 1. The IPR System

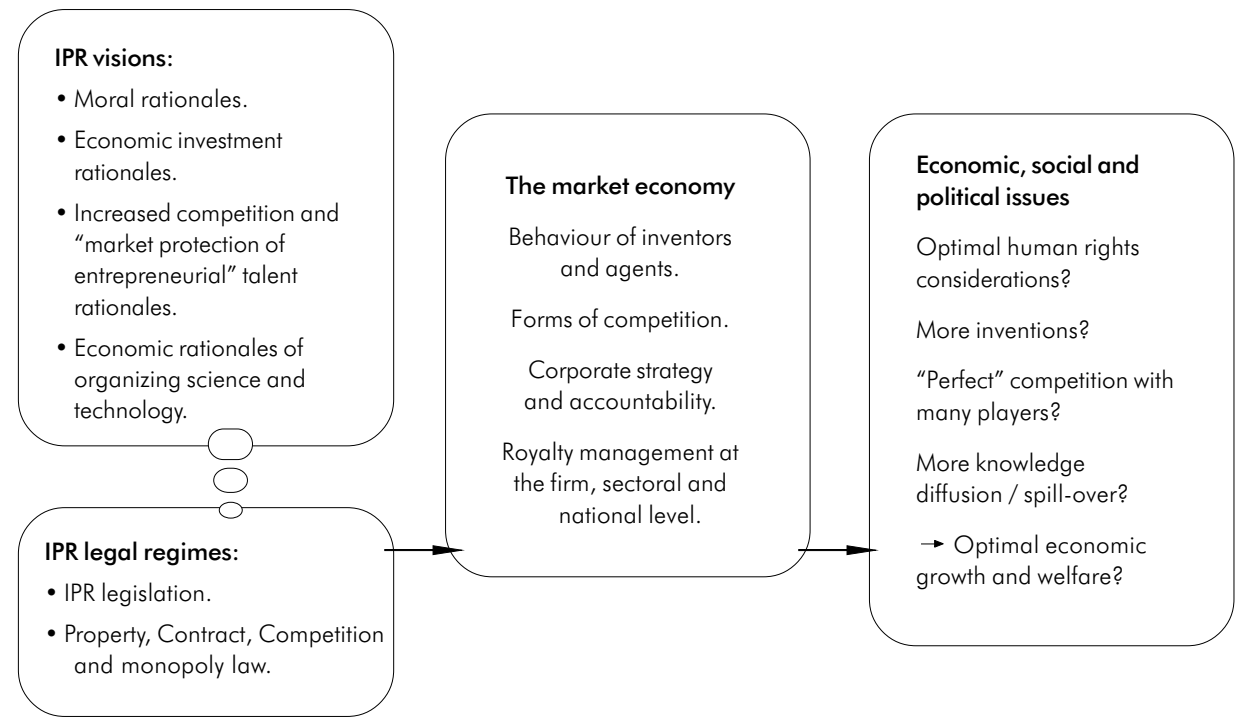

The article stresses that it is the creation of institutions and infrastructures from social interaction in competitive markets that explain why some technologies win the competitive game and why some corporations become leading. The article illustrates how the patent regime tend to be a "winner takes all"-system, so it can encourage corporate strategies to create patent blocking 
and fast lock-in to technological and institutional frameworks in order to control or protect market advantages, instead of searching for optimal solutions and thereby increase overall welfare. That is, patents (especially in the new electronic age) can enforce creation of suboptimal technological and economic solutions, provide a platform for unfair exploitation of individuals and sectors of the economy, that subsequently have to adapt to established technological trajectories or paradigms, and create major corporate concentration in industries rather than competition with many players.

Also, the practical aspects of managing and enforcing patent rights (including the costs of such activities) in the micro-electronic digital age is not self-evident. Although a rationale or an objective of IPRs might be to strengthen the sectoral innovation system, improve corporate and industrial performance, enhance competition and corporate and industrial competitiveness, protect market advantages, etc; the ownership of an IPR portfolio is only worth something if it is "managed properly" and enforced at the firm, sectoral and national level. The problem is not merely that unused patents are not worth anything or that we need to develop IPRs in "promising" fast growing technological areas (which was constantly stressed in the 1980s and 1990s), but that for the third millennium enterprise patents have become an important asset for income generation and value creation through licensing and positioning. Thus, firms and sectors need to understand and to be able to manage the complex mechanisms regarding the way rent is generated and captured from such value-driven intellectual capital.

Finally, although the patent controversies in this article have mainly been confronted in relation to the new electronic techno-economic paradigm, the arguments should of course be applied more widely. 


\section{References}

Andersen, B. et al., Knowledge and Innovation in the New Service Economy. Cheltenham: Edward Elgar, 2000.

, Technological Change and the Evolution of Corporate Innovation: The Structure of Patenting 1890-1990. Cheltenham: Edward Elgar, 2001.

Arrow, K., "Economic Welfare and the Allocation of Resources for Inventions", in The Rate and Direction of Inventive Activity: Economic and Social Factors, Princeton, N.J., National Bureau of Economic Research, p.609-625, 1962.

Arthur, B., "Competing technologies: an overview”. In Dosi, G.; Freeman, C.; Nelson, R.; Silverberg, G.; Soete, L. (eds.), Technical change and economic theory. London: Pinter Publishers, p.590-607, 1988.

, "Increasing Returns and the New World of Business", Harvard Business Review, July-August, 1996.

Cheung, S. "Property Rights and Invention". In Palmer, J. (ed.), Research in Law and Economics: The Economics of Patents and Copyrights, v. 8, p. 5-18, 1986.

David, P. , "CLIO and the Economics of QWERTY", in American Economic Review, 75 (2), 332-37, 1985.

; Olsen, T., “Technology adoption, learning spillovers, and the optimal duration of patent-based monopolies". In International Journal of Industrial Organization, 10, $517-$ 543, North-Holland, 1992.

, "Will building 'good fences' really make 'good neighbours' in Science". Report to European Commission (DG-Research) STRATA-ETAN workshop on IPR aspects of internal collaborations, 2001.

EU. EU's hearing on "Industrial Property" and "The Economic Impact of Patentability of Computer Programs”, 2002, see http://europa.eu.int/comm/internal market/en/ indprop/studyintro.htm

Kitch, E., "The Nature and Function of the Patent System”, Journal of Law and Economics, XX (1), April, 265-90, 1977.

Machlup, F.; Penrose, E., “The Patent Controversy in the Nineteenth Century”, Journal of Economic History, X (1), May, 1-29, 1950.

Merges, R.; Nelson, R., “On the Complex Economics of Patent Scope”, Columbia Law Review, 90 (1), January, 839-961, 1990. 
Monopolies and Mergers Commission, The Supply of Recorded Music: A report on the supply in the UK of pre-recorded compact discs, vinyl discs and tapes containing music, London: HMSO, 1994.

Plant, A., "The Economic Theory Concerning Patents for Inventions", in Economica, 1, February, New Series, 30-51, 1934.

Posner, R., “The Economic Theory of Property Rights: Static and Dynamic aspects”, "Extracts from Property" in Economic Analysis of Law, 4th ed., Toronto: Little, Brown and Company, 32-39, 1992.

Rivera-Batiz, L.; Romer, P., "Economic Integration and Endogenous Growth", in The Quarterly Journal of Economics, May, 1991.

Rivette, K.; Kline, D., Rembrandts in the Attic: Unlocking the hidden value of patents. Mass: Harvard Business School University Press, 2000.

Towse, R.; Holzhauer, R. (eds.), The International Library of Critical Writings in Economics. The economics of Intellectual Property, Vol I, II, III and IV. Cheltenham: Edward Elgar, 2002.

Winter, S., "Patents and Welfare in an Evolutionary Model", in Industrial and Corporate Change, v. 2, November, 211-231, 1993. 